\title{
Synthesis and characterization of nanofluids from the biosynthesis of nanoparticles and their evaluation in solar thermal systems
}

\author{
Asmat-Campos, D. ${ }^{1,2, *}$,Avalos-Vera ${ }^{3}$,Delgado-Alfaro ${ }^{3}$, Gutierrez-Hoyos $^{3}$, Jacinto-Paredes $^{3}$, Reyes-Zavaleta ${ }^{3}$ \\ ${ }^{1}$ Universidad Privada del Norte (UPN), Dirección de Investigación y Desarrollo, Trujillo 13001, Perú. \\ ${ }^{2}$ Universidad Privada del Norte (UPN), Grupo de Investigación en Ciencias Aplicadas y Nuevas Tecnologías, Trujillo, Perú. \\ ${ }^{3}$ Universidad Privada del Norte (UPN), Carrera de Ingeniería Industrial, Trujillo, Perú.
}

\begin{abstract}
The objective of the study was to evaluate diverse and known types of heat transfer fluids (water, oil and glycerin) commonly used in solar thermal systems, in this work denoted as base fluids, with respect to them, but with the addition of biosynthesized metal nanoparticles. It was considered a prototype of solar heating systems by thermosiphon in the application-experimental phase assisted by halogen light (with wavelengths ranging from deep infrared to violet). The process of biosynthesis or green synthesis of silver nanoparticles (NP Ag) was from the precursor of silver nitrate $\left(\mathrm{AgNO}_{3}\right)$ and using as a reducer the alcoholic extract from agroindustrial residues of the wine production, obtaining colloids with high monodispersity and with sizes between 30 and $40 \mathrm{~nm}$. (spherical geometry). The results suggest a greater increase in heat absorption capacity when biosynthesized silver nanoparticles are added to the oil, which managed to have a heat capacity of $3519.41 \mathrm{~J} / \mathrm{kg}^{\circ} \mathrm{C}$
\end{abstract}

\section{Introduction}

At present there is a vital interest in solar-based systems, since thermal energy [1] can be obtained for different applications such as generating steam or hot water to processes [2]; on the other hand, the performance of the fluids that are commonly used in solar collectors has a low thermal conductivity [3] and reduced capacity of solar radiation absorption, in addition to its operation it is required the use of fossil fuels [4], main source of greenhouse gases which promotes global warming causing damage to climate, environment and human health [5]. For these reasons, it is desired to increase the performance of such devices using nanoparticles [6] dispersed in bionanofluids [7], carrying out experimentation processes and application analysis in order to evaluate their positive effect on solar heating systems.

On the other hand, in nature it has been found that biomolecules [8] actively participate in the formation of nanoparticles, which allows the development of safe and beneficial techniques for the environment. The use of organic waste materials [9] not only reduces the costs of this process, but also reduces the use of hazardous chemical reagents. Carlos Campos Leyton [10], synthesized different types of nanofluids and evaluated the effect of each of them on the absorption of solar radiation [11]. Among the nanoparticles studied are those of gold, silver, copper and graphene oxide (GO) dispersed in deionized water and not biosynthesized. For this, nanofluids are characterized by electron microscopy and visible UV spectra. The thermal conductivity is measured and the nanodispersions [12] are subjected to solar radiation obtaining the temperature profiles. Obtaining thus, that all the synthesized nanofluids show an improvement in the capacity of absorption of visible light [13] and in the thermal conductivity in comparison with the deionized water. In addition, it is obtained that for a mass concentration of $0.01 \%$ the low oxidation gold, silver, copper and GO nanofluids reach an equilibrium temperature of $5^{\circ} \mathrm{C}$ higher than the base fluid when subjected to simulated solar radiation [14]. Regarding green synthesis or biosynthesis, there are a variety of techniques which have come to determine an efficient influence of organic radicals such as anthocyanins and reducing sugars responsible for the process of reducing the precursor agent, which is how they have used an extract in the aqueous state of cranberry (Vaccinium corymbosum L.) [15], obtaining nanoparticles with spherical geometry and diameters of 9.74 and $13.67 \mathrm{~nm}$, with moderate monodispersity, but high stability, becoming an alternative of sustainable synthesis unlike inorganic or chemical that causes a high environmental impact for being polluting.

Similarly, there are other organic materials used as reducing agents in the synthesis of silver nanoparticles with reed root (Rumex hymenosepalus) [16], producing $15 \mathrm{~nm}$ nanoparticles of average size with typical cubic structure; the orange peel (Citrus sinensis), showing a remarkable variation in size with temperature. Amit K. Mittal et al. They collected the results of many works in which plant extracts were used as reducing agents due to 
their polyphenolic components [17], finding a variety of biosynthetic pathways that produce nanoparticles of various forms with low polydispersity [18]. Concluding that the use of plant extracts allows a control of the size and morphology of the nanoparticles, however, in the collected works no one was found where grape bagasse extracts are used.

This article shows the results of the elaboration of silver nanoparticles following a green synthesis [19], which uses as a reducing agent extract of agroindustrial residues from wine production in alcoholic state, to evaluate the effect of absorbance thermal in heat transfer fluids. The nanoparticles were evaluated by characterization techniques by UV-Vis spectrophotometry, transmission electron microscopy (TEM), while the evaluation of the heat transfer fluids was by means of temperature data logger sensors.

\section{Material and methods}

Three sections have been considered, the first linked to the green synthesis (biosynthesis) of silver nanoparticles, and the second related to obtaining nanofluids, finally a description of the experimental research evaluation protocol is made.

\subsection{Green synthesis of silver nanoparticles}

For this process, the green chemistry method was used, having as a precursor to silver nitrate $\left(\mathrm{AgNO}_{3}\right)$ at a concentration of $1 \mathrm{M}$ in dilution of $10 \mathrm{~mL}$ of ultrapure water, with the aim of preparing a stock solution to subsequently extract $50 \mathrm{uL}$ and improve it at $50 \mathrm{~mL}$, obtaining the ideal concentration for the synthesis process. This process was carried out in the hotplate - stirring at a temperature of $60^{\circ} \mathrm{C}$ for 10 minutes and at 300 revolutions per minute.

Subsequently, the extract of agroindustrial grape residues from wine production was added dropwise, which proved to be an excellent reducer because it has phenolic groups, which are demonstrated in the results section with FTIR technique characterization. Final step, the solution was brought to $\mathrm{pH} \mathrm{10,} \mathrm{obtaining} \mathrm{a} \mathrm{dark}$ brown solution. (Fig. 1).
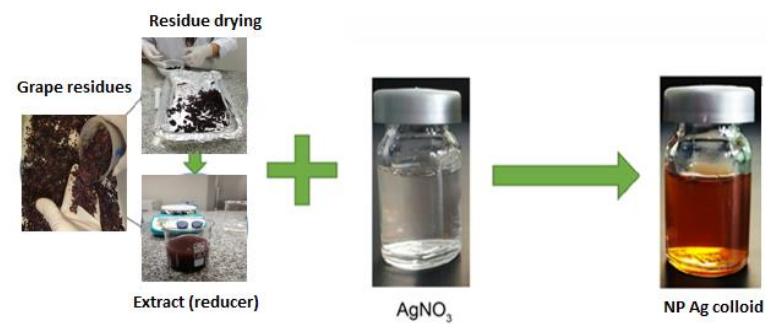

Fig. 1. Biosynthesis protocol of silver nanoparticles.

\subsection{Nanofluid synthesis}

For the preparation of nanofluids, glycerin, distilled water and oil based fluids were started, to which the biosynthesized silver nanoparticles colloid with a total value of $30 \mathrm{~mL}$ per sample was added, all with the volume concentration ratio 2: 1 . It should be noted that the colloid concentration of silver nanoparticles was not decreased. The samples were prepared at room temperature $\left(23^{\circ} \mathrm{C}\right)$ and constant stirring by stirring (300 RPM) for a time of 15 minutes.

\subsection{Evaluation of base fluids and nanofluids}

As a first activity, samples of all heat-carrying fluids (base fluids and nanofluids) were evaluated by interaction with the direct radiation of the halogen light to the medium, which were in thermally isolated Petri dishes $(30 \mathrm{~mL})$ for 30 minutes. The temperature data were with a sensor with data logger programmed so that every 5 minutes it keeps a data of the process of temperature increase in ${ }^{\circ} \mathrm{C}$; the data was obtained in a spreadsheet and then plotted and analyzed in Origin software (Fig. 2).

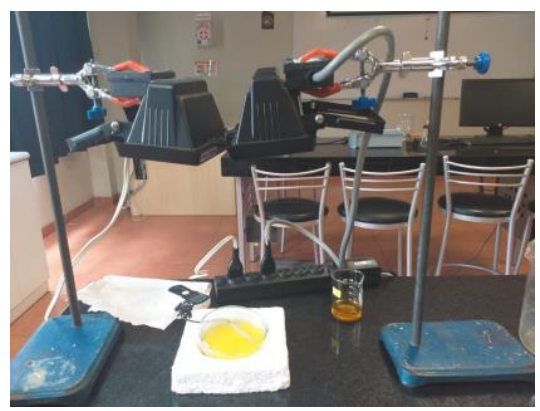

Fig. 2. Evaluation of the temperature gradient of the heat transfer fluids by direct radiation to the study solution.

As a second activity, the amount of heat contributed to an internal environment by the heat transfer fluids under study was analyzed, for this purpose a solar house prototype was built with a radiant floor heating system (Fig. 3), which had a flat solar collector located at the top of the experimental scheme. Copper pipe heat transfer fluid was considered as a means of transport because it has a high coefficient of thermal conductivity (372.1 $385.2 \mathrm{~W} / \mathrm{K} . \mathrm{m})$. The environment had thermal insulation (teknoport). The temperature measurement was made with a sensor with data logger, simultaneously with another sensor where it evaluated the outside temperature (ambient temperature), both for a time of 1 hour (60 minutes) and calibrated for data acquisition every 5 minutes; The results were then downloaded to a spreadsheet and plotted in Origin software.

\section{Results and discussion}

The results are the result of the evaluation of the process of green synthesis or biosynthesis of silver nanoparticles, for this case the residues of the wine production were used at a concentration of $1 \mathrm{mM}$. The nanoparticles obtained were evaluated by the UV-Vis spectrophotometry technique, obtaining exactly the location of the plasmon floor and its proper absorbance, which suggests at first the presence of silver nanoparticles; The colloid was also evaluated by the Transmission Electron Microscopy (TEM) technique which revealed the approximate geometry and size. 
The results of the colloid analyzed by UV-Vis spectrophotometry indicate the presence of silver nanoparticles, because according to Fig 4 the peak is located at $422.61 \mathrm{~nm}$. And an absorbance of 1.78 u.a. The location of the plasmon resonance peak assured us the formation of NP Ag.
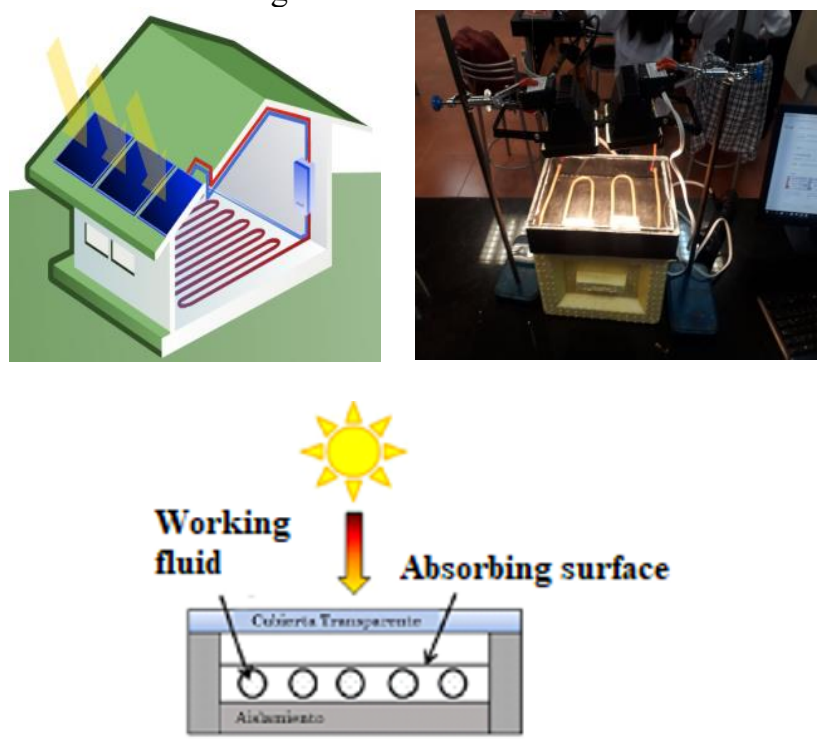

Fig. 3. Experimental scheme for the evaluation of the thermal behavior of heat transfer fluids.

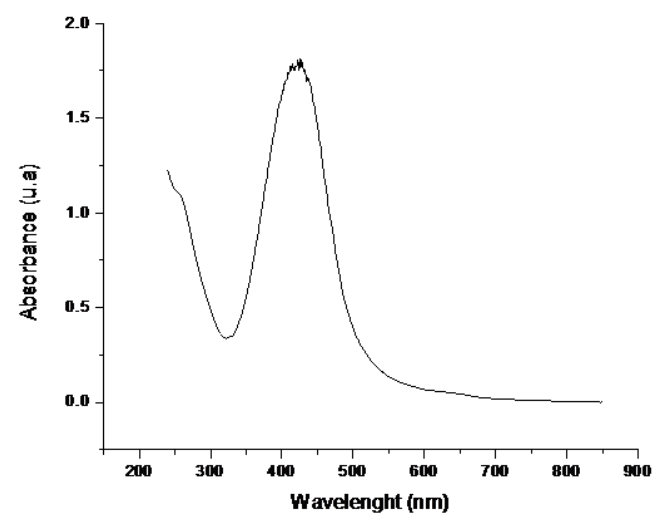

Fig. 4. Optical absorbance spectrum of biosynthesized NP Ag.

The colloid was analyzed by transmission electron microscopy (TEM), which confirms its geometry, being spherical, with high monodispersity and an average diameter of $32.66 \mathrm{~nm}$. (Fig. 5)

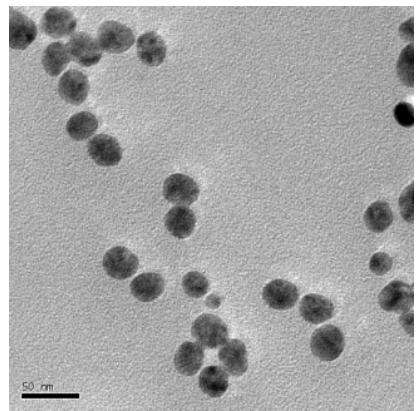

Fig. 5. Transmission electron microscopy of silver nanoparticles synthesized with alcoholic grape residue extract.

As a complement to the investigation, the reducing effect of the extract of agroindustrial waste from wine production was analyzed, because this is part of the nanoparticle formation process, since it is part of the precursor Silver Nitrate $\left(\mathrm{AgNO}_{3}\right)$ which must be be reduced, for this the extract was analyzed by the FTIR characterization technique (Fig. 6), where it gives us information about the location (peaks) characteristic of some organic radicals and therefore determine the possible compounds responsible for the reduction process.

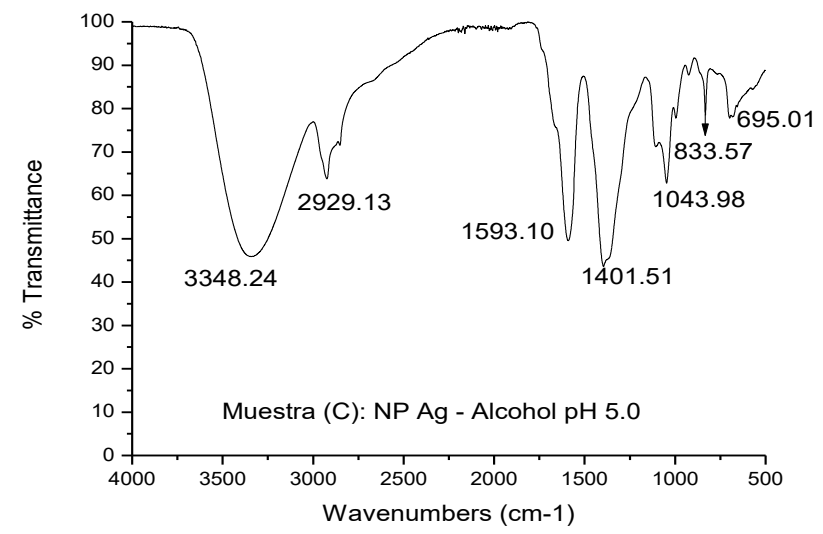

Fig. 6. FTIR spectrum of the grape residue extract sample.

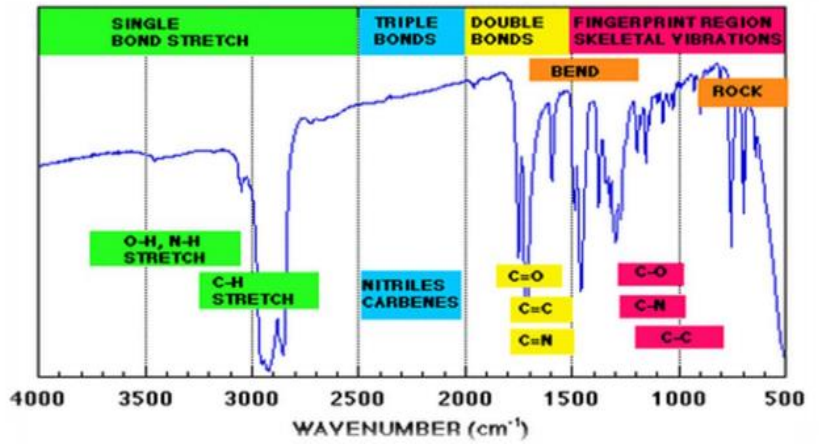

Fig. 7. Spectral scanning of FTIR analysis where the radicals can be visualized depending on the position of the peaks.[20]

The infrared spectrum of the residues of the wine production, which was previously crushed and lyophilized, is observed in Fig. 6 and compared with Fig. 7 [20] leads us to highlight the presence of polyphenolic compounds in the band in $1593.1 \mathrm{~cm}-1$ characteristic of the deformation in the plane of the $\mathrm{OH}$ bond of polyphenols, and the characteristic $1401.5 \mathrm{~cm}-1$ band of flavonols, in addition the presence of this family of compounds is evidenced by characteristic bands of gallic and tannic acids in 695.01, $1043.98 \mathrm{~cm}-1$.

Regarding the analysis of heat transfer fluids as described in the methodology section, fluids subjected to direct halogen lamp radiation were initially evaluated, and the temperature measurement was also directly in the sample, in order to evaluate initially the efficiencies in heat absorption and speed of the temperature gradient increase. Below is the analysis of the heating rate of heat transfer fluids based on their temperature increase, these data were taken every 5 minutes. (Fig. 8). 


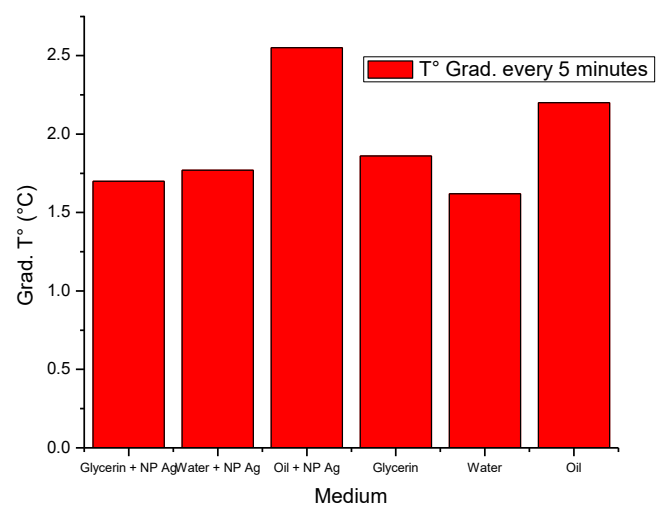

Fig. 8. Evaluation of the temperature increase speed depending on the type of heat transfer fluid.

As can be seen in the previous figure, the combination of the oil + NP Ag is the one that most rapidly increases its temperature, this at a rate of $2.55^{\circ} \mathrm{C}$ every 5 minutes, and being the lowest in the case of water, at a rate of $1.62{ }^{\circ} \mathrm{C}$ every 5 minutes, it should be noted that these results correspond to samples with the same volume, concentration, medium and intensity of radiation. It is also possible to visualize the compartment mentioned in Fig. 8 and Fig. 9.

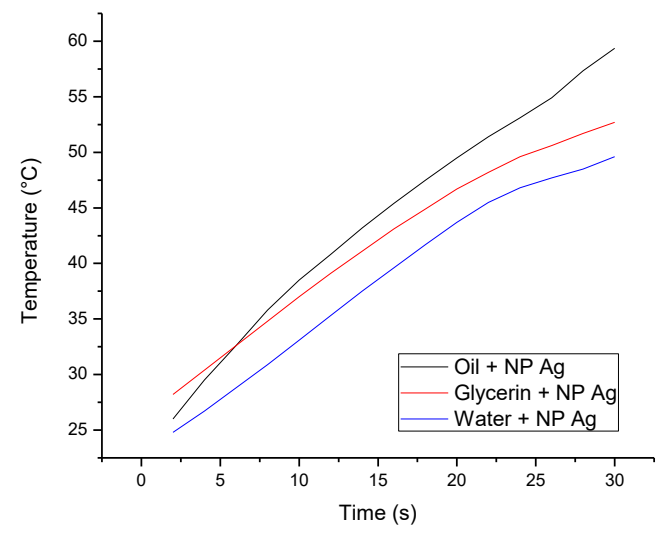

Fig. 9. Evaluation of the temperature increase of nanofluids.

Fig. 9 shows the behavior of heat absorption and its temperature gradient evaluating only the nanofluids, it can be seen that the case oil + NP Ag is the one that has the best performance, for this the specific heats of the three nanofluids under study and known data from the other three base fluids under study were considered, the same as detailed in Table 1.

Table 1. Specific heat (Cp) of heat transfer fluids under study.

\begin{tabular}{|l|c|}
\hline \multicolumn{1}{|c|}{ Heat transfer fluid } & $\mathbf{C p}\left(\mathbf{J} / \mathbf{k g}^{\circ} \mathbf{C}\right)$ \\
\hline Water + NP Ag & 6591.37 \\
\hline Glycerin + NP Ag & 4442.22 \\
\hline Oil + NP Ag & 3519.41 \\
\hline Water & 4186 \\
\hline Glycerin & 2410 \\
\hline Oil & 2000 \\
\hline
\end{tabular}

Analyzing only the context of nanofluids, it can be seen that depending on the proportionality ratio of equation 1, density and $\mathrm{Cp}$ are IP, and just as the density increases (due to the presence of the base fluid) the $\mathrm{Cp}$ decreases, than analyzing The theoretical results of $\mathrm{Cp}$ in the case of oil is that which has a value of $3519.41 \mathrm{~J} / \mathrm{kg}^{\circ} \mathrm{C}$ being lower compared to the other two nanofluids, that indicates that it is the heat transfer fluid that needs less heat provided to the system so that it can be increased $1^{\circ} \mathrm{C}$ as temperature gradient.

$$
C_{p}=\frac{Q}{\rho V \Delta T^{\circ}}
$$

Analyzing the cases of base fluid (Oil $2000 \mathrm{~J} / \mathrm{kg}^{\circ} \mathrm{C}$ ) with the nanofluid (Oil + NP Ag $3519.41 \mathrm{~J} / \mathrm{kg}^{\circ} \mathrm{C}$ ), theoretically it would be 'ideal' to only use the base fluid (oil) for having less $\mathrm{Cp}$, without However, it is necessary to differentiate something important, since the specific heat does not have a relation with the thermal conductivity this because it is closely related to the 'electron', however the specific heat ( $\mathrm{Cp}$ ) is mainly due to the vibrations of the ions ( phonons) (Debye model), this is how an increase in equilibrium temperature can be evidenced when the fluid contains NP Ag, since they have even greater thermal conductivity [21] with respect to the base fluid; the improvement could be attributable to the addition of metal nanoparticles, which have a high thermal conductivity, which also implies increasing the effective thermal conductivity of the dispersion [22], two additional aspects can also be considered, the first one to improve the thermal conductivity, the heat produced by the radiation absorption is conducted faster inside the nanofluid, and the second one related to the fact that metal nanofluids have a greater absorption capacity in the visible range of metal nanofluids (NP Ag 410-430 nm) compared to the other base fluids that is minimal.

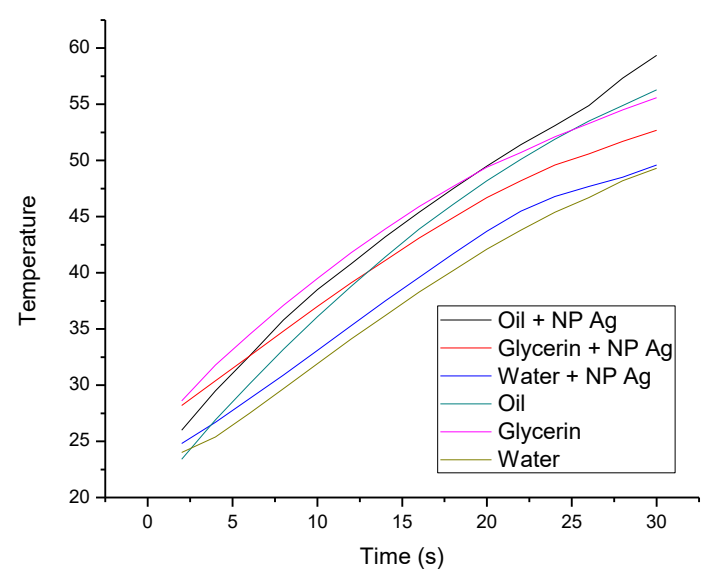

Fig. 10. Evaluation of the temperature increase of all heat transfer fluids under study.

In Fig. 10, it is possible to demonstrate the efficiency of the nanofluid oil $+\mathrm{NP} \mathrm{Ag}$, since its temperature increases faster compared to the other heat transfer fluids, however, there is an important detail, if we compare the nanofluid glycerin $+\mathrm{NP} \mathrm{Ag}$ versus the base fluid 'glycerin', we observe that an inverted process occurs, when silver colloid (NP Ag) is added the heat capacity of the medium decreases.

In the second experimental protocol (Fig. 3), a solar heating system with radiant floor assisted by a flat solar 
collector was evaluated, with the objective of evaluating which of the heat transfer fluids is the one that has the best thermal behavior from the emission of heat by radiation.

Fig. 11 shows the results of the temperature variation in an internal environment due to the effect of heat transmission by radiant floor system; The system was thermally insulated and the heat source was assisted by two halogen lamps.

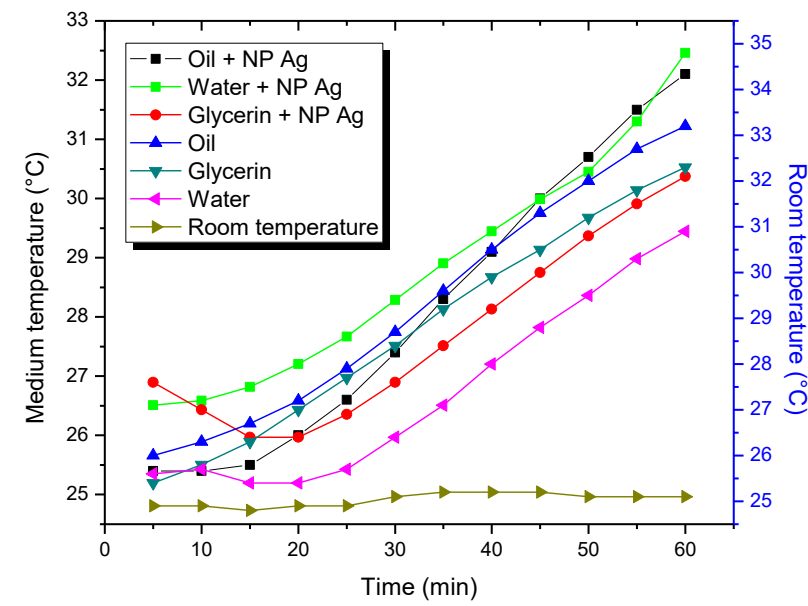

Fig. 11. Evaluation of the thermal behavior by radiation in a radiant floor heating system.

As evidenced in Fig. 10, the measurement of the absorption of the caloric intake and the rate of temperature increase was in favor of the nanofluid oil + NP Ag, now in graph 11 the temperature gradient is evaluated as a product of the energy transmitted by radiation (radiant floor heating system), where we observe that for the same case (oil + NP Ag) there is a rapid increase in temperature, starting from $25.5^{\circ} \mathrm{C}$ and finally arriving (after one hour ) at $31.9^{\circ} \mathrm{C}$, there is an identical behavior in the case of the nanofluid water $+\mathrm{NP}$ Ag sample, whose graphs tend to be intercepted at $29.5^{\circ}$ $\mathrm{C}$, however it is notorious that in this case the speed of temperature increase is much lower. Definitely for all heat-carrying fluids there is a significant improvement with respect to the ambient temperature, which for this case in this research paper highlights those fluids that have a considerable speed to generate an increase in temperature and the heat energy absorption capacity provided -in real cases- by solar energy.

As discussed in previous sections, specific heat has a direct implication, being synonymous with vibration at the level of quasiparticles subjected to vibratory kinetics, this due to the caloric contribution of the external medium, however it is evident that nanofluids, especially the Oil solution + NP Ag is the one that needs less caloric intake to generate a rapid increase in temperature. The cases of base fluids have a deficiency not because they have - perhaps - a low specific heat value but would analyze the thermal conductivity at the molecular level given by the behavior of electrons.

Finally, the nanofluid samples were analyzed by UVVis spectrophotometry (Fig. 12), where it can be denoted that the nanoparticles have not undergone any modification as a result of having mixed them with a medium under conditions of presence of other types of base fluids, which had the possibility of having generated some modification in the silver colloids. In the case of the nanofluid based on oil + NP Ag, only a decrease in plasmonic peak is noted, this is due to the fact that a total homogenization of the solution was not generated due to the density differences, since the characterization mentioned was made at room temperature, which implies that when it is at a higher temperature the homogenization is much higher. Fig. 12.

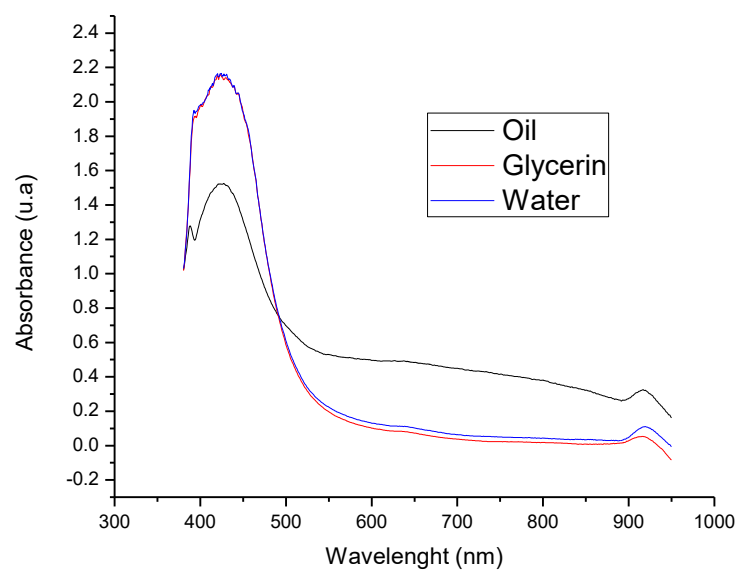

Fig. 12. Nanofluid Spectrophotometry

\section{Conclusions}

The methodology of green synthesis of silver nanoparticles was successful, this was achieved using as a reducing agent the extract of residues from wine production; FTIR analyzes determined that the presence of polyphenols and flavonols were those involved in the reduction process of the silver nitrate precursor $\left(\mathrm{AgNO}_{3}\right)$ to achieve nanostructures with spherical geometry, the spectrophotometry characterization determined the presence of the plasmon resonance peak at $422.61 \mathrm{~nm}$, typical of the nanostructure under study, in addition TEM images demonstrate high monodispersity. The results of the study related to heat transfer fluids applied to solar thermal systems (radiant floor heating system) showed in the cases of water + NP Ag and oil + NP Ag to have a good behavior to transport and emit heat by radiation, being the best is the case of oil + NP Ag with a temperature increase of $0.6{ }^{\circ} \mathrm{C} / 5 \mathrm{~min}$. , and for the temperature gradient measured directly in the fluid achieved a speed of $2.55{ }^{\circ} \mathrm{C} / 5 \mathrm{~min}$. and a specific heat of $3519.41 \mathrm{~J} / \mathrm{kg}^{\circ} \mathrm{C}$. In fact, nanofluid (as a heat transfer fluid oil + NP Ag) is a good candidate to apply in solar thermal systems, specifically in geographic sectors where the intensity of solar radiation is low, because it would need less caloric intake so that it can increase their temperature.

\section{References}

1. Arroyo, M. (2008). Nuevas fuentes de energía para un futuro sostenible ¿Petróleo caro o protección del medio?. X Coloquio Internacional de Geocrítica. 
Universidad de Barcelona. Downloaded : http://www.ub.edu/geocrit/-xcol/143.htm

2. O.A. Jaramillo. (2017). Energía solar térmica de mediana temperatura para calor de proceso. Instituto de energías renovables. México. Downloaded : http://www.cie.unam.mx/ ojs/pub/Enernight/Energia \%20Solar\%20Calor\%20Proceso\%20OJS.pdf

3. Sánchez, J. (2012). Diseño de colectores solares de placa plana por efecto termosifón. (Tesis de Maestría). Centro de Investigación en Materiales Avanzados, México.

4. Frías, T. (2012). Colector térmico fotovoltaico interconectado a la red. (Tesis de Maestría). Centro de Investigación en Materiales Avanzados, México.

5. Weart, S. (2007). El calentamiento Global. Revista de Ambiente y Desarrollo, 23(3), 81-82

6. Cruz, D., Rodríguez, M., López, J. \& Col. (2012). Nanopartículas metálicas y plasmones de superficie: Una relación profunda. Avances en Ciencia e Ingeniería, 3(2), 67-78.

7. Mondragón, R., Juliá, J., Barba, A., \& col. (2014). Preparación y caracterización de nanofluidos: Influencia de variables sobre su estabilidad, estado de aglomeración y propiedades físicas. Boletín de la Sociedad Española de Cerámica y Vidrio, 53(3), 101-110.

8. Macarulla, J., Goñi, F. (1984), Biomoléculas, Lecciones de Química Estructural, España, Barcelona, Editorial Reverté.

9. Couto, I., Hernández, A., \& col. (2012). La gestión integral de los residuos sólidos urbanos en Juárez: Lecciones innovadoras para otros municipios. Revista Pueblos y Fronteras Digital. 7(13), 178-2009.

10. Campos, C. (2018). "Efecto de distintos nanofluidos en la absorción de radiación solar", (trabajo doctoral), Santiago de Chile.

11. Barros, B. (2005). El cambio climático global. Buenos Aires, Argentina, Editorial Libros del Zorzal.

12. Jianhui Li, Qing Tan Jing-Feng Li. (2013). BiSbTe-Based Nanocomposites with High ZT: The Effect of $\mathrm{SiC}$ Nanodispersion on Thermoelectric Properties. Adv. Funct. Mater. 23(35), 4317-4323
13. Deepali Sharma, (2015). Biogenic synthesis of nanoparticles: A review, Journal of Chemistry, S1878-5352(15)00314-7.

14. Galicia, A., Arrieta, J., Landa, L. (2007). La medición de la absorción de luz de soluciones químicas, una práctica social de ingenieros bioquímicos. Acta latinoamerica de matemática educativa, 20, 490-495

15. Asmat-Campos, D., Delfín-Narciso \& col. (2019). Green synthesis and characterization of silver naniparticles, by the reductive action of the aqueous extract of blueberry (Vaccinium corymbosum). Laccei proceeding. DOI: http://dx.doi.org/10.18687/LACCEI2019.1.1.92

16. Alvarez, F. (2015). Síntesis de nanopartículas de plata empleando extractos de raíz de la cañagria (Rumex hymenosepalus) y sus efectos abtimicrobianos. (Tesis de Grado). Universidad de Sonora, México.

17. Tomás-Barberán. (2003). Los polifenoles de los alimentos y la salud. Alimentación, nutrición y salud. 10(2), 41-53.

18. Hernández, H., Aguirre, J., (2005). Estimación de calidad en polímeros empleando sensores virtuales. Dyna. 72(147), 65-73.

19. Salinas-Estevané, Sánchez, E. (2012). La química verde en la síntesis de nanoestructuras. Ingenierías, 15(54), 7-16.

20. Díaz, M. (2016). Obtención de polifenoles en endemismos canarios. (Tesis de Grado). Universidad de la Laguna.

21. Campos, C. (2018). Efecto de distintos nanofluidos en la absorción de radiación solar. (Tesis de Grado). Universidad de Chile, Chile.

22. X. Q. Wang y A. S. Mujumdar, "Heat transfer characteristics of nanofluids: a review", Int. J. Therm. Sci., vol. 46, no 1, pp. 1-19, 2007. 